\title{
PENSAR DESDE EL CUERPO: EL NUEVO TEATRO DE EL SALVADOR EN LA DÉCADA DE 1970
}

\author{
RICARDO ROQUE BALDOVINOS \\ Universidad Centroamericana José Simeón Cañas, El Salvador
}

\begin{abstract}
RESUMEN: A partir de un recuento del movimiento teatral en El Salvador durante la efervescencia revolucionaria de la década de 1970, el presente artículo discute distintas estéticas teatrales de vanguardia preocupadas por desarrollar un pensamiento desde el cuerpo. Examinando los conceptos centrales del teatro épico de Brecht y sus continuadores latinoamericanos (Enrique Buenaventura, Santiago García y Augusto Boal) y enmarcándolos en el debate estético sobre sus implicaciones (Benjamin, Jameson, Rancière), intenta mostrar que el nuevo teatro pone en evidencia la producción social del cuerpo como mecanismo de subjetivación y las posibilidades de emancipación que se abren a través de las nuevas formas de experimentarlo que ofrecen los nuevos vocabularios dramáticos.
\end{abstract}

PALABRAS CLAVE: estética; teatro; vanguardia; autoritarismo; revolución; Latinoamérica; El Salvador.

\section{Thinking from the body: New Theater in El Salvador in the 1970s}

ABSTRACT: Starting with a survey of the theatrical movement in El Salvador during the revolutionary turmoil of the 70s, this article discusses different Avant-Garde theatrical aesthetics concerned in developing a practice of thinking from the body. Engaging in a discussion with the main concepts of Brecht epic theatre and its Latin American followers (Enrique Buenaventura, Santiago García y Augusto Boal) and the aesthetic debate about their implications (Benjamin, Jameson, Rancière), this article demonstrates that New Theatre evidences the social production of the body as mechanism of subjectivation and the emancipatory possibilities of new forms of bodily experience offered by the new dramatical vocabularies.

KEY WORDS: aesthetics; theatre; Avant-Garde; autoritarianism; revolution; Latin America; El Salvador.

Puede ser que el teatro no sea revolucionario en sí mismo, pero no tengan dudas: ¡es un ensayo de la revolución! Augusto Boal ${ }^{1}$

En 1971, Roberto Salomón, director del Departamento de Artes Escénicas del recientemente fundado Bachillerato en Artes en El Salvador, visitó Colombia acompañado de tres artistas y pedagogos del teatro que se habían integrado al proyecto gracias a un convenio de cooperación con la España franquista ${ }^{2}$. El propósito del viaje era conocer de primera mano el método de creación

1 Boal, A., Teatro del oprimido, México, Nueva Imagen, 1980, p. 59.

2 Salomón, R., Entrevista personal con el autor, 18/2/2013; SAlomón, R., "Análisis de la situación del patrimonio artístico en El Salvador. Área: Teatro», informe realizado para la Fundación Accesarte, 2012, disponible en: <http://plataformadecultura.com/web/category/ analisis-de-situacion-de-la-expresion-artistica-de-el-salvador/> [31/5/2018]. 
colectiva del Teatro Experimental de Cali (originalmente Teatro Escuela de Cali, mejor conocido por sus siglas TEC) y el Teatro de la Candelaria de Bogotá. Pensaba aplicar esa metodología en El Salvador. Salomón provenía de una acomodada familia salvadoreña de origen judío y había realizado estudios en los Estados Unidos. Sus últimos años de formación los había pasado en el Dramatic Workshop (Taller Dramático), institución fundada por Erwin Piscator en sus años de exilio y adscrita a la New School of Social Research ${ }^{3}$. Para entonces, era uno de los grandes centros del método stanislawskiano. Salomón lo había estudiado a fondo, pero no estaba satisfecho con el énfasis psicologista y un tanto dogmático del Workshop. Animado por el espíritu contracultural de la revuelta del 68, tenía otras ideas sobre el teatro. Era necesario superar la centralidad del texto y la suprema autoridad del director. La dinámica del teatro tradicional donde el actor recita y se mueve siguiendo la inspiración del director era la expresión del orden cultural caduco. La creación debía generarse desde la actuación, en un teatro que viera la creación como el momento, el instante de la interpretación y no en los textos de la gran literatura dramática. Buscaba también algo que estuviera en las antípodas del teatro de corte tradicional que se venía haciendo en El Salvador.

Por eso, cuando en 1970 Walter Béneke, el Ministro de Educación, lo nombró en la dirección del Bachillerato en Artes Escénicas en el nuevo programa de Bachilleratos en Artes, hizo gestiones para renovar sus planes de estudio y su planta docente. Partió en misión oficial a España y reclutó a Antonio Malonda, Yolanda Monreal y Jesús Sastre, quienes provenían del movimiento de teatro contestatario que estaba cobrando auge pero que, a menudo, debía enfrentarse a la rígida censura oficial ${ }^{4}$. Recientemente habían montado como parte de un grupo denominado Bululú Teatro, El mito de Segismundo, una adaptación libre y cargada de alusiones políticas del clásico de Calderón de la Barca, La vida es sueño ${ }^{5}$. Por añadidura, la obra había obtenido un premio en el Festival Internacional de Zagreb, del otro lado de la cortina de hierro. Les resultó entonces prudente alejarse temporalmente de España, que sufría los últimos espasmos represivos del franquismo, y trasladarse a América Latina, donde estaban sucediendo cosas interesantes ${ }^{6}$.

Si pudiéramos señalar un lugar desde donde irradiaba la renovación del teatro para América Latina, ese lugar sería Colombia. El teatro allí había tenido escaso desarrollo, y hasta la década 1950, era más bien provinciano y

3 SALOMÓN, R., Entrevista citada.

4 Salomón, R,, Entrevista; Huezo, R., Entrevista personal con José Manuel González, 20/2/2013. CAÑÉNGUEZ, D., Entrevista personal con el autor, 7/2/2013.

5 Currículo profesional de Antonio Malonda, en: < http://www.adeteatro.com/detalle_socio.php?id_socio=163> [31/5/2018].; VALladARES, N., Entrevista personal con el autor, 25/11/2013.

6 Cañénguez, o, c; Salomón, o, c. 
convencional ${ }^{7}$. Hasta que, según cuenta Santiago García, uno de los fundadores del Teatro de la Candelaria, el dictador Rojas Pinilla hizo venir a Seki Sano, un director y profesor japonés radicado en México ${ }^{8}$. Su misión era entrenar actores, no para el teatro, sino para la recién fundada Televisión Nacional. Sano era un internacionalista japonés cuyos azares revolucionarios lo había llevado a conocer de primera mano las propuestas dramatúrgicas de Konstantin Stanislavsky y Vsevolod Meyerhold en la Unión Soviética, y de Erwin Piscator y Bertolt Brecht en Alemania, para finalmente establecerse en México en 1939. Con su síntesis de lo mejor de la formación del método de Stanislawski y la biomecánica de Meyerhold, Seki Sano tuvo un papel activo en la profesionalización del teatro de su nuevo país ${ }^{9}$. Otro tanto logró en Colombia, pero por más breve tiempo, pues cuando el régimen militar supo de su pasado revolucionario procedió a expulsarlo sin demoras. Pero su paso, según Santiago García, dejó un germen que prosperó. Paradójicamente, la fragilidad de la institución teatral colombiana fue un terreno fértil para el surgimiento de un movimiento teatral novedoso, que no tardó en ser uno de los puntos irradiadores de la cultura radical de izquierdas.

Así se resume el itinerario laberíntico que lleva de El Salvador a Colombia, pasando por Japón, Alemania, los Estados Unidos y la Unión Soviética. Pero sería un error decir que se trata solo de un problema de influencias o de recepción. Resulta útil aquí mencionar a Roberto Schwarz y su propuesta de las «ideas fueras de lugar» que nos recuerda que los dispositivos culturales adquieren valencias distintas según sea el entorno específico donde se inser$\tan ^{10}$. En El Salvador, al igual que en Colombia, el nuevo teatro se incubó bajo la protección de un régimen militar, pero luego se vinculó al movimiento revolucionario. Era un teatro que arrancaba bajo el amparo de los proyectos de modernización autoritaria, pero que estableció luego estrechos vínculos con los movimientos populares.

En esta conexión entre estética y política, el nuevo teatro se arraigó en El Salvador. Allí, durante un breve período adquirió un esplendor especial. Se conviertió en un movimiento que afirmaba la fuerza de lo que Jorge Alemán llama lo excéntrico ${ }^{11}$. Lo excéntrico desafía lo metropolitano, pero también ex-

7 Aldana, J., «Consolidación del campo teatral bogotano. Del Movimiento Nuevo Teatro al teatro contemporáneo» en: Revista colombiana de sociología, No. 30, 2008, pp. 111-134.

8 GARCía, S., «El movimiento teatral en Colombia», en Teoría y práctica del teatro, Ediciones La Candelaria, Bogotá,1989, pp.106-107.

9 TANAKa, M., «Seki Sano and Popular Political and Social Theater in Latin America» en: Latin American Theatre Review, Spring (1994), pp. 53-69.

10 Schwarz, R., "Las ideas fuera de lugar», en: Meridional, Revista Chilena de Estudios Latinoamericanos, Número 3, octubre 2014, pp. 183-199.

11 Jorge Alemán propone esta sugerente distinción entre lo periférico y lo excéntrico para explicar el gran aporte de Jorge Luis Borges al debate sobre la relación entre la cultura europea y la llamada periferia <https://www.youtube.com/watch?v=4Au4yED9dHE > [31/5/2018]. Al afirmar que desde el margen puede asumir la cultura como totalidad y no desde los prejuicios de los particularismos nacionales europeos, Borges afirma que el movimiento 
cede lo periférico, figura esta última atrapada en una lógica de plenitud y carencia. Se puede puede afirmar que es una verdadera potencia creativa, o para emplear otra figura distinta, de antropofagia, en el sentido del «Manifiesto Antropofágico» que Oswald de Andrade promovió a comienzos del siglo XX en el Brasil, satirizando el tropo colonialista del «caníbal» que devora al colonizador para crear algo nuevo ${ }^{12}$.

El desarrollo de este nuevo lenguaje artístico aspira a algo muy ambicioso en el ámbito estético: idear un método que propone pensar desde el cuerpo, en un movimiento que no sólo desafía la dualidad cuerpo-mente, sino que tiene como meta la producción de un nuevo cuerpo $^{13}$. El lenguaje teatral, en una tradición que abarca desde los ejercicios a biomecánica del constructivismo soviético pasando por el método brechtiano hasta las distintas apropiaciones latinoamericanas, interviene en las tecnologías de subjetivación, en la producción de cuerpos socializados, que pasa por un doble momento de desubjetivación y de nueva subjetivación, o para decirle en términos de Jacques Rancière, el paso de una comunidad estética que abre la vía a la constitución de un nuevo sujeto político, el protagonista de la revolución por venir. Era por esta razón que el brasileño Augusto Boal veía, en el teatro, un ensayo de la revolución.

Los actores abordaban los autobuses temprano en la mañana, a la hora en que los habitantes de la ciudad se dirigían a sus centros de trabajo. Uno de ellos atraía la atención de los pasajeros al comentar en voz alta alguna noticia del periódico sobre los sucesos políticos del momento. Otro lo contradecía con tono apasionado, si era necesario un tercero se enganchaba, hasta provocar que los pasajeros se involucraban en la discusión. Cuando el intercambio de palabras se había convertido en un auténtico debate político, los actores se retiraban silenciosamente y dejaban que el autobús siguiera su destino. Se trataba de una representación teatral cuidadosamente ensayada, pero que nunca se revelaba como tal al público. Así lo recuerda Donald Paz, uno de esos jóvenes involucrados, quien participó del entonces floreciente movimiento teatral independiente que gravitaba alrededor de un programa oficial pionero de educación artística, el Bachillerato en Artes, en su opción de Artes Escénicas ${ }^{14}$. Este programa era parte del nuevo esquema de políticas culturales iniciadas durante el gobierno del general Fidel Sánchez Hernández. Los estudiantes de teatro se mantenían al día y discutían las últimas corrientes del movimiento teatral mundial, en

del pensamiento en realidad no reconoce centro y está a disposición para ser apropiado y recreado desde cualquier lugar.

12 Subirats, E., Una última visión del paraíso, Fondo de Cultura, México, 2004, pp. 75-82.

13 La idea del lenguaje teatral como método de crítica social la retomo del libro JAMESon, F., Brecht and Method, Verso, Londres y Nueva York, 1998.

14 PAZ, D., Entrevista personal con el autor, 29/8/2013. 
especial los vientos de cambio que llegaban desde América del Sur. Todo esto sucedía a mediados de la década de 1970 en la ciudad de San Salvador, período especialmente convulso, cuando se estaba gestando un amplio movimiento popular que luchaba contra un régimen político dominado por los militares y un modelo de modernización autoritaria que, a esas alturas, estaba llegando a sus límites ${ }^{15}$.

El ejercicio teatral antes referido era parte de las propuestas de Augusto Boal, uno de los mayores representantes del Nuevo Teatro Latinoamericano. El cineasta Noe Valladares, otro antiguo estudiante del Bachillerato en Artes Escénicas, afirma que el propio Boal había discutido esta técnica en unas charlas cuando estuvo de visita en El Salvador ${ }^{16}$. El «teatro-bus» era una adaptación local del «teatro invisible», una de las formas de realizar el teatro como discurso, es decir la etapa superior del método dramático del autor brasileño, donde se echaba a andar la praxis liberadora fuera del recinto teatral. En Teatro del oprimido, lo define así:

«Consiste en la representación de una escena en un ambiente que no sea el teatro y delante de personas que no sean espectadoras. El local puede ser un restaurant, una cola, una calle, un mercado, un tren, etc... Las personas que asisten a la escena son las personas que allí se encuentren accidentalmente. Durante todo el espectáculo estas personas no deben tener la más mínima conciencia de que se trata de un "espectáculo» pues esto las transformaría en "espectadoras" " [...] El teatro invisible explota en un determinado local de gran influencia. Todas las personas que están cerca quedan involucradas en la explosión, y los efectos de ésta perduran hasta mucho después de terminada la escena» ${ }^{17}$.

Más adelante aclara:

«Hay que insistir en que el teatro invisible no es lo mismo que un happening o el llamado guerrilla-theatre: en estos casos queda claro que se trata de "teatro" y por lo tanto surge inmediatamente el muro que separa actores de espectadores y éstos son reducidos a la impotencia» ${ }^{18}$.

La magia del teatro invisible consiste, pues, en ocultar su carácter de espectáculo. Sólo así se garantizaba su efectividad, es decir, al resonar entre los espectadores-actores y se convertía en germen revolucionario. Revelar su artificio habría sido letal porque levantaría de nuevo el muro divisorio que separa actor

15 Turcios, R., Autoritarismo y modernización. El Salvador 1950-1970, Dirección de Publicaciones e Impresos, San Salvador, 2003.

16 Valladares, N., Entrevista Personal con el autor, 29/11/2013. El propio Boal hace referencia a esta experiencia en su Teatro del oprimido: «El grupo argentino con el que había realizado el teatro invisible hizo lo mismo en San Salvador, en América Central: sin tren, pues allí no existe red ferroviaria, en autobús... jautobús-teatro!» (243). El grupo argentino es Once al Sur, que también se involucró en la enseñanza en el Bachillerato en Artes a comienzos de la década de 1970.

17 BOAL, o, c, pp. 44-45

18 BoAl, o, c, 48. 
del espectador, sería reducir a los nuevos testigos a espectadores y condenarlos de nuevo a la impotencia. Porque, al menos en este pasaje, se manifiesta que el espectáculo es la poética de la opresión que la nueva propuesta se propone superar.

Boal incurre así en la crítica del espectáculo que denuncia Jacques Rancière en El espectador emancipado ${ }^{19}$. En dicho ensayo, el filósofo francés elabora una crítica demoledora al nuevo teatro y las enseñanzas de su figura más notoria, Bertolt Brecht, referente central del nuevo teatro latinoamericano. Rancière señala dos críticas presentes en la tradición teatral de vanguardia. La del teatro épico de Brecht que demanda un espectador activo y racional; y la del teatro de la crueldad de Antonin Artaud que propone la eliminación del espectáculo, pues el espectador es absorbido por el espectáculo.

El supuesto detrás de todo es la identidad entre comunidad y teatro, que resulta de la presencia física en un mismo espacio de los cuerpos de los actores y el público. La crítica del espectáculo se dirige hacia algo que impediría la verdadera realización de la comunidad, pues la crítica del espectáculo ve además en el teatro una relación pedagógica y repite la pedagogía tradicional. Tras la denuncia de la pasividad del espectador se aspira solapadamente a eliminar la mediación de los signos, que enturbia la comunicación directa entre maestro y estudiante, entre autor/director/actor y público. Esta visión del teatro intenta saltarse una mediación que, después de todo, pone en evidencia la no pasividad del espectador. La densidad del signo se percibe como un obstáculo a la ambición de poder de los promotores del nuevo teatro de programar directamente los comportamientos de la audiencia en esa encarnación momentánea de la comunidad. La crítica del espectáculo del teatro de vanguardias aspira a saltarse de la experiencia estética equívoca y aterrizar directamente en una subjetivación unívoca. La eliminación de la opacidad de la mediación, y consecuentemente de la decisión del espectador, sería parte de una pedagogía vertical y autoritaria.

Clave para comprender la política del nuevo teatro que nos interesa en el presente trabajo es determinar hasta qué punto esta crítica le hace justicia. Para ello, trataremos de establecer si la posibilidad de un pensamiento desde el cuerpo no es una mera una ilusión epifánica. Rancière tiene razón al señalar que la mediación semiótica rompe cualquier posibilidad de una programación directa y calculable de las respuestas del público. Pero considero que en la dramática del nuevo teatro hay una visión de la corporalidad que no escamotea la mediación, sino que precisamente aspira a evidenciarla en toda su densidad. Conviene para ello revisemos brevemente en el método brechtiano y sus reformulaciones latinoamericanas.

Para comenzar en este esfuerzo, hay que admitir la reflexión sobre el nuevo teatro aporta abundante evidencia que confirma la crítica de Rancière. Una

19 Rancière, J., El espectador emancipado, Manantial, Buenos Aires, 2010. 
muestra de ello es el siguiente pasaje del epígrafe que encabeza el Teatro del oprimido:

«Teatro era el pueblo cantando al aire libre: el pueblo era el creador y el destinatario del espectáculo teatral, que podía entonces llamarse teatro ditirámbico. Era una fiesta de la que todos podían participar libremente. Vino la aristocracia ... Y estableció divisiones: algunas personas irán al escenario y sólo ellas podrán actuar; las demás se quedarán sentadas, receptivas, pasivas: éstos serán los espectadores, la masa, el pueblo» ${ }^{20}$.

Es una idea que se reitera en más de una ocasión en el libro y que ilustra de la manera un tanto bochornosa la archipolítica que permea mucho del nuevo teatro, la ilusión de vuelta a una comunidad de origen, previa a toda mediación. Boal invoca un colectivo carismático que habrá de volver una vez se haya logrado romper el daño de la caída en la historia que marcó la frontera que separó público y actores, en la brecha entre escenario y público audiencia de espectáculo. Sin embargo, habida cuenta de esta encendida retórica, en otra parte de sus escritos, introduce una dimensión mucho más interesante y concreta de su técnica teatral. Como veremos más adelante, el trabajo del teatro es evidenciar la construcción social del cuerpo. La apelación al cuerpo no es así un atajo para escamotear la mediación del signo, sino en el objeto de operaciones sociales inscritas en la semiótica del cuerpo.

Santiago García relaciona esta problemática con un elemento central de la teoría brechtiana: el gesto [Gestus]. Con el término "gesto» Brecht intenta designar algo más que códigos no verbales corporales. La idea es que el gesto como la disposición corporal de los personajes en el momento de actuar permite evidenciar cómo lo social se hace presente más allá del contenido explícito de la escena. El gesto sintetiza así una visión de la corporalidad del teatro que no elude la mediación del signo y de la cultura. Según nos recuerda Fredric Jameson, para Brecht el teatro no era la ilusión ideológica de la presencia de la comunidad, sino todo lo contrario: el esfuerzo por caer en la cuenta de que la actuación es una dimensión inescapable de la vida social y cotidiana, en otras palabras, de que todos somos actores ${ }^{21}$. El concepto de gesto nos permite entender que el cuerpo está atravesado por los signos, por la historia, por la mediación técnica que subjetiva de las maneras más imperceptibles pero decisivas a los miembros de una sociedad.

Precisamente lo que Brecht reprochaba al teatro artistotélico y su política de la identificación de la catarsis era eliminar la visibilidad de dicha mediación como resultado la fusión empática de espectador con los personajes. Para Brecht, lo reprensible no era el espectáculo en sí, sino aquel que oculta el artificio. Boal, a través de una lectura especialmente lúcida de la Poética de Aristóteles,

20 BOAL, O, c, p. 11.

21 JAMESON, O, c, p. 25. 
explica de manera elocuente que la empatía entre actor y personaje de la catarsis es un eficaz mecanismo de control social de los afectos ${ }^{22}$.

Para romper con esta dinámica, el gesto interrumpe deliberadamente el flujo de la acción teatral, pues la empatía depende de que el espectador se sumerja en ese fluir. Con la interrupción, se pretendía mostrar que la vida social no se puede expresar un encadenamiento simple de acciones individuales. Uno de los primeros en comprender que romper el continuo empático de la trama aristotélica era vital para comprender las nuevas formas de vida colectiva fue Walter Benjamin. Por ello, afirma que: «[e]ste teatro épico [...] no tiene que desarrollar acciones, tanto como representar situaciones $»^{23}$. La acción nos remite al continuo de la ilusión de inmediatez, mientras que la situación, revela los múltiples vectores que operan en el comportamiento observable de los sujetos. En síntesis, las acciones no responden a una motivación que emana de las intenciones o las emociones de los protagonistas, sino de una múltiple causalidad social.

Siempre que se habla de Brecht se menciona que su gran aporte al lenguaje y la teoría teatral es el efecto de distanciamiento [Verfremdung Effekt o V-Effekt]. Para Fredric Jameson, el distanciamiento y el gesto del teatro épico no son una simple negación como se ha aceptado entre los comentaristas del dramaturgo alemán, sino dispositivos de diferenciación, que apuntan hacia las múltiples dinámicas que convergen y se abren en la actuar humano ${ }^{24}$. Es a partir de allí que ofrece avenidas a emancipación si bien, habría que conceder a Rancière, estas no tienen que ser únicas ni muchos menos estar prescritas.

La crítica de Brecht a la poética aristotélica resuena asombrosamente en el trabajo más reciente de Rancière sobre la novela ${ }^{25}$. Allí rechaza la teoría del realismo de Lukacs para la cual lo más importante en la novela es una trama donde operan héroes típicos que condensan nítidamente las contradicciones fundamentales de una sociedad. Para Rancière, la disolución de la trama en el estilo en novelistas como Joseph Conrad o Virginia Woolf no es incapacidad de aprehender la «totalidad» ni mero virtuosismo formalista, sino un verdadero hallazgo de técnica narrativa que permite captar una lógica de lo social que ya no depende de los planes de los «hombres de acción», sino de la convergencia de múltiples factores, donde se equilibra el peso de los personajes pequeños y grandes, pero también donde operan fuerzas no-personales.

Podemos afirmar, siguiendo el vocabulario del propio Rancière, que el gesto es en realidad un mecanismo de disenso, donde se propone un nuevo arreglo entre lo visible, lo pensable y lo decible, lo que abre nuevas posibilidades de percibir el mundo y de actuar sobre él. Estos momentos disensuales operan como poderosos mecanismos de desubjetivación, de ruptura con las identidades sociales dadas. Pero, también posibilitan comunidades estéticas, colectivos

22 BOAL, o, c, pp. 107-153.

23 Benjamin, Tentativas sobre Brecht (Iluminaciones III), Madrid, Taurus, 1990, p. 19.

24 JAMESON, F., O, c. pp. 35-51; 79-85.

25 RANCIÈRE, J., El hilo perdido, ensayos sobre ficción moderna, Manantial, Buenos Aires, 2014. 
donde se comparte una nueva sensibilidad emergente, condición necesaria, mas no suficiente de nuevas subjetivaciones políticas ${ }^{26}$.

Jochen Schulte-Sasse aclara que la teoría sobre el teatro que conocemos de Brecht en realidad formaba parte de una "pequeña pedagogía» ${ }^{27}$. Esta era su intervención «revolucionaria» en la institución dramática moderna, de cuyos límites era plenamente consciente. Brecht vislumbraba, sin embargo, una «gran pedagogía» que excedía la demarcación de la institución teatral. Esto se revela en los detallados ejercicios y comentarios que Brecht elabora sobre sus ensayos. Allí parecía que la educación política y artística de los actores, a través de una detallada atención sobre su cuerpo, se convertía en una experiencia mucho más importante que la realización del espectáculo mismo ${ }^{28}$.

La realización de la ambición de esta «gran pedagogía» en la producción de un nuevo cuerpo social es la que se abre para sus seguidores latinoamericanos por las condiciones propias de su mundo que afectan la inserción de los dispositivos del nuevo teatro. De ello era testimonio el teatro bus del que hablábamos antes, pero esta no es, ni por cerca, la experiencia más interesante que emerge para cuando examinamos las propuestas del nuevo teatro latinoamericano y los testimonios de sus participantes.

\section{III}

La actriz Ana Ruth Aragón realizó las audiciones para ingresar al Bachillerato en Artes Escénicas en su nativa ciudad de Santa Ana. Para garantizar que la convocatoria de ingreso del programa incluyera jóvenes de extracción popular y de los distintos puntos de la geografía nacional, los coordinadores de ese programa programaban audiciones en las principales ciudades del país. Los seleccionados recibirían becas completas que les permitiría dedicarse a tiempo pleno a adquirir la formación artística deseada. Ana Ruth llegó vistiendo sus mejores galas, como si se tratase de participar en una de las numerosas veladas escolares donde desde niña había mostrado sus aptitudes para el canto, el baile y la declamación. Desafiaba los deseos de sus padres, que esperaban que siguiera en una carrera útil, como secretariado comercial, que le asegurase al menos su lugar en la clase media. Pero los examinadores le pidieron hacer cosas inesperadas. Hubo de tirarse al piso para interpretar algún animal, realizar piruetas y pruebas de voz más que bailar o cantar. Terminó desarreglada y con la

26 Rancière, J., «Aesthetic Separation, Aesthetic Community», en Rancière, J., The emancipated spectator, Verso, Londres y Nueva York, 2009, pp. 51-82. Es de notar que este capítulo no se incluye ni en la versión original francesa del libro, ni en su traducción al español.

27 Schulte-Sasse, J., «Introduction», in Szondi, P., Theory of the Modern Drama, University of Minnesota Press, Mineapolis Press, 1997, pp. vii-xvi.

${ }_{28}$ Willet, J. (ed.), Brecht on Theatre, Hill and Wang/Methuen, Londres y Nueva York, 1964, pp. 209-275. 
ropa sucia ${ }^{29}$. El actor Francisco Cabrera, oriundo de la pequeña aldea de Sitio del Niño, hizo las audiciones en la capital ese mismo año, en $1970^{30}$. Uno de los examinadores le pidió que se imaginara que era un auto que se estrellaba. Se lanzó con tal violencia contra su examinador que le hizo sangrar la nariz. Era un joven de origen campesino, tímido, acostumbrado a actuar sumisamente, a no hacerse notar, en otras palabras, a aceptar la exclusión. Con el percance de su examinador, sintió que sus sueños de estudio se le venían por tierra. Trató de disculparse. El examinador lo calmó diciéndole con fuerte acento español «iNo es nada, hombre!». Era Jesús Sastre, parte del trío que había venido a reforzar el Bachillerato ${ }^{31}$. En el programa que se había diseñado para la especialidad en teatro tendría a su cargo la cátedra de Acrobacia Dramática.

Esos ejercicios representaban un enfoque totalmente novedoso en la formación dramática conocida hasta entonces. La actriz Isabel Dada, perteneciente a una generación anterior, había tenido por mentor a Edmundo Barbero, artista dramático del exilio español, contemporáneo de la generación del 27, radicado en El Salvador y, por ese entonces, director del Teatro Universitario. Durante sus más de veinte años de estancia en el país, al frente de ese grupo y del Elenco Estable de la Compañía Nacional de Teatro, formó una nueva generación de actores y renovó el repertorio teatral. Pero su lenguaje dramático era el tradicional, el que se empleaba para llevar a las tablas las grandes obras de la literatura dramática. Según Dada, el maestro explicaba a los actores el personaje, les ayudaba a analizarlo y les daba la "entonación» y las "posiciones»" 23 . La propuesta del Bachillerato en Artes, en cambio, cambiaba totalmente el enfoque. Siguiendo las ideas de las nuevas corrientes desplazaba el centro del texto dramático y la voz al cuerpo del actor. Los nuevos maestros insistían al estudiantado que el principal instrumento de trabajo sería su cuerpo, que había que educarlo y cuidarlo. Incluso les prohibían la práctica de deportes fuertes como el fútbol, para prevenir lesiones. Para entrenar el cuerpo que requería la nueva dramaturgia, se habían elaborado cursos como Acrobacia Dramática o Juegos Escénicos. Incluso Expresión Oral, que impartía la norteamericana Susan Leich, abordaba la voz como algo físico y les ayudaba a asumir la voz como realidad corporal ${ }^{33}$.

La idea de incorporar la acrobacia a la didáctica teatral se encuentra ya en Konstantin Stanislawski. Es una técnica que facilita la improvisación, le permite al actor construir su personaje más allá de lo literal del texto dramático ${ }^{34}$. Pero la propuesta de educación corporal del Bachillerato en Artes pretendía

29 ARAGón, A. R., Entrevista personal con el autor, 29/11/2013.

30 Sitio del Niño es una pequeña población que pertenece al municipio de Colón, Departamento de La Libertad, distante apenas unos 25 kilómetros de la capital, pero en esos tiempos era todavía una zona rural.

31 CABRERA, F., Entrevista personal con el autor, 25/10/2013.

32 DADA, I., Entrevista Personal con el autor, 22/5/2013.

33 Aragón, A. R., Entrevista.

34 Stanislawski, K., An Actor's Work [1934], trad. Jean Benedetti, Londres y Nueva York, 2008, p.358. 
más, pues se nutría de las nuevas metodologías de la creación colectiva y de las lecturas de la dramaturgia brechtiana que estaban teniendo lugar en el seno del nuevo teatro latinoamericano. Como hemos visto antes, las acciones de la fábula siempre debían estar situadas, encarnarse en un contexto social concreto y tangible.

El paso del texto al cuerpo era considerado un paso hacia la emancipación por Enrique Buenaventura, el fundador del Teatro Experimental de Cali, cuando cita al historiador italiano del teatro Ferdinando Taviani. Este, a propósito, de la Commedia dell'Arte, afirma que:

«[1]a idea que ha prevalecido en el teatro occidental es aquella —extrañísima si la miramos bien- según la cual el espectáculo es la puesta en escena de un texto [...] Como se ve, es una idea que parece derivar no de la concreta vida teatral sino de la ideología jurídica o religiosa, que concibe el "texto" como algo inamovible en su forma, en la "letra", e interpretable en la sustancia, en su espíritu» ${ }^{35}$.

A lo que luego Buenaventura añade:

«[e]s posible que tal ideología jurídica o religiosa tenga que ver con el origen de esa "extrañísima" idea. Parece, sin embargo, que la división del trabajo que precede y sigue a la revolución industrial, aquella que ordena las relaciones de producción como relaciones entre los que "conciben" y los que "ejecutan", ejerció una decisiva influencia»"

Buenaventura plantea de manera un tanto distinta a la de Boal la legitimación del orden que realiza el teatro tradicional. Ya no es un problema de la división de actores y espectadores, sino del control del sentido de la obra en la división del trabajo teatral. Y esta visión quedaba legitimada por reificación del teatro como "género literario». El teatro, afirma de manera tajante Buenaventura, no es "un género literario», es "un sistema de textos o códigos (visuales y sonoros) que no puede producirse sin la mediación de los espectadores, que sólo existe en la relación particular de estos, puesto que esa relación le da toda la dimensión de espectáculo vivo, único e irrepetible». El teatro es, pues, un acontecimiento donde actores y espectadores se colocan ante el despliegue de pone una pluralidad de códigos. Los más importantes están relacionados con la corporalidad. De esta manera, Buenaventura introduce la lógica de diferenciación que explicamos antes con la teoría del gesto.

Ya en una aplicación práctica de estas teorías en el proceso de entrenamiento de los nuevos actores del Bachillerato, Noé Valladares recuerda que el maestro español Antonio Malonda sostenía que la técnica corporal liberaba la mente. La acrobacia, por ejemplo, estaba dirigida a romper con la represión interiorizada. Malonda veía la represión que habitaba los cuerpos de los estudiantes

35 Buenaventura, E., «Actor, creación colectiva y dramaturgia nacional» en: Boletín Cultural y Bibliográfico de la Biblioteca Luis Arango, XXII (1985), s/p. Disponible en: <https:// publicaciones.banrepcultural.org/index.php/boletin_cultural/article/view/3246> [31/5/2018].

36 Ibid. 
salvadoreños. Les decía que cuando les daba instrucciones los veía que se iban encogiendo ${ }^{37}$. Era la represión interiorizada de una sociedad autoritaria y rígida. Por eso, los ejercicios teatrales eran ejercicios de liberación, pero no tanto porque facilitaban cierta ideología o interpretación del mundo, sino porque les permitía a los implicados entrar en una experiencia de disensualidad, es decir ocupar nuevos lugares, sentirse capaces de hacer cosas nuevas. No sólo de adquirir destrezas artísticas o profesionales, sino aprender a interpretar la realidad autointerpretándose. Francisco Cabrera valora esa experiencia pues le hizo superar las inhibiciones de su socialización campesina, que define como «el mundo del no», es decir de naturalización de la desigualdad ${ }^{38}$.

Esta pedagogía corporal emancipadora se encuentra plenamente desarrollada en la propuesta de técnica teatral de Augusto Boal:

«Podemos afirmar que la primera palabra del vocabulario teatral es el cuerpo humano, principal fuente de sonido y movimiento. Por eso, para dominar los medios de producción del teatro, el hombre tiene en primer lugar que dominar su propio cuerpo, conocer su propio cuerpo para después poder tornarlo más expresivo. Estará entonces habilitado para practicar formas teatrales en que por etapas se libera de su condición de "espectador" y asume la de "actor", en que deja de ser objeto y pasa a ser sujeto, en que de testigo se convierte en protagonista ${ }^{39}$.

El nuevo teatro aspira la constitución de un nuevo cuerpo, el cuerpo emancipado de la disciplina social que lo oprime y distorsiona. De esa manera, el sujeto adquiere la habilidad de hablar con su cuerpo y de iniciar un camino de liberación:

"Si uno es capaz de desmontar sus propias estructuras musculares será seguramente más capaz de "montar" estructuras musculares propias de otras profesiones o "status" sociales, es decir, estará más capacitado para "interpretar" físicamente otros personajes diferentes de sí mismo» ${ }^{40}$.

En realidad, esta experiencia de disenso estético que posibilitó la intensidad de la vinculación política del nuevo teatro. Ya no se trataba de transmitir contenidos revolucionarios o de dejarse instrumentalizar en la función propagandística por alguna organización política, sino de vivir la política de una forma más intensa y radical.

Donald Paz y Fernando Umaña habían tenido experiencias de militancia política antes de su ingreso al Bachillerato en Teatro. Ambos descubrieron en el

\footnotetext{
37 Valladares, N., Entrevista.

38 Cabrera, F., Entrevista.

39 Boal, A., Teatro del oprimido, p. 22.

40 Boal, A., Teatro del oprimido, p. 25.
} 
lenguaje dramático el canal natural para sus inquietudes personales y políticas. Encontraron una profunda afinidad entre el trabajo escénico y la experiencia del organizador popular en el calor de la manifestación ${ }^{41}$. Clave en esta inflexión hacia la política del proyecto teatral es la experiencia que traen algunos estudiantes desde sus propias experiencias de rebeldía social. No es casualidad que temprano en los procesos de subjetivación estética de algunos artistas de ellos aflora su pasión por la danza ${ }^{42}$. La danza es un lenguaje que permite al cuerpo escapar de los hábitos de la disciplina social, de la dominación internalizada del ethos autoritario, la postura sumisa del ciudadano dócil. Así se establece pues un parentesco entre danza, teatro y política. Pero la experiencia que marca también el destino del nuevo teatro salvadoreño de manera más decisiva es la vivencia de la militancia. Recordemos que desde comienzos de la década de 1970 se forma una intensa actividad organizativa entre los estudiantes de secundaria. En estas organizaciones habían militado Paz y Umaña.

Esta afinidad del teatro y la política la destaca Walter Benjamin cuando explica el teatro épico como una suerte de pérdida del aura en el dominio dramático. Lo dice manifiestamente cuando afirma en la primera versión de su ensayo "¿Qué es teatro épico?», que el foso que separa la escena del público ha perdido su distancia religiosa:

«Esta escena ya no representa a su público "las tablas que significan el mundo" (por tanto, un espacio mágico) sino un lugar de exposición favorablemente situado. Su público ya no significa una masa de personas en las que se ensaya el hipnotismo, sino una reunión de interesados cuyas exigencias ha de satisfacer ${ }^{43}$.

Se mantiene una nueva distancia, pero es la de la escena que se eleva en podio. Así lo aclara en la segunda versión del mismo ensayo:

«La escena está todavía elevada, pero ya no emerge de una hondura inescrutable: se ha convertido en podio. La pieza didáctica y el teatro épico son una tentativa de instalarse en el podio ${ }^{44}$.

Pero para entender plenamente la relación entre escena dramática y escena política en la experiencia teatral salvadoreña hay que retraerse unos cuantos años. Al momento en que el teatro se inserta en la política cultural de la modernización autoritaria. En este encuentro fortuito de circunstancias que hicieron posible el nuevo teatro salvadoreño, cabe destacar otra conexión japonesa, además de la de Seki Sano que vimos al principio. Walter Béneke, el ministro de Educación que impulsó el proyecto del Bachillerato en Artes Escénicas, había fungido en un período anterior como embajador de El Salvador ante el Japón. Sentía una especial admiración por ese país, tanto por su cultura ancestral

\footnotetext{
41 Umaña, F., Entrevista personal con el autor, 15/3/2013; Donald, P., Entrevista.

42 Donald, P., Entrevista; Cañénguez, D., Entrevista.

43 Walter, B., o. c., p. 18.

44 Benjamin, o, c, p. 40.
} 
como también por su vertiginosa modernización ${ }^{45}$. De hecho, otra de sus creaturas será la Televisión Educativa, un ambicioso proyecto de masificar la educación media ${ }^{46}$. Irma Lanzas, su primera directora, cuenta que la idea la extrajo Béneke de los usos educativos de ese medio en el país oriental ${ }^{47}$. Pero Béneke se había sentido deslumbrado por el teatro Nô y el Kabuki. Recordemos que esas expresiones, en las cuales se sintetizan de manera elaborada diferentes lenguajes artísticos también fascinaron antes a artistas de vanguardia como Sergei Eisenstein. No es pues arriesgado aventurar que la fascinación por la televisión y el teatro atestiguan una apuesta por el poder cohesionador y renovador de cierto tipo de espectáculo, de un nuevo lenguaje de síntesis que es a la vez cifra y estímulo de la modernización.

Ahora bien, el carisma y la habilidad política de este singular personaje no explican por sí solos los recursos considerables que logró atraer a su propuesta de reingeniería de la institucionalidad artística oficial. Hábilmente, Béneke y su grupo de colaboradores pudieron convencer los poderes de la necesidad de nuevas estrategias para relanzar un proyecto de modernización autoritaria que estaba siendo retado desde varios frentes. Estaba, por un lado, la oposición que ejercían tanto la izquierda, hegemonizada por un Partido Comunista proscrito, pero activo a través de distintas máscaras; y, por otro, el recientemente formado Partido Demócrata Cristiano, que operaba legalmente y estaba ganando puestos electos a nivel de gobiernos locales y de la Asamblea Legistlativa. Pero se presentaba además un adversario de nueva índole: el movimiento contracultural juvenil. El sector estudiantil había sido uno de los soportes tradicionales de la oposición al régimen militar, pero el movimiento contracultural estaba cohesionando un descontento y un rechazo que no coincidía necesariamente con las expresiones políticas tradicionales. El mismo éxito del proyecto de modernización autoritaria había ampliado considerablemente la población «juvenil». El crecimiento de las clases medias significaba, entre otras cosas, el aumento de una población que tenía acceso al ocio, el consumo mediático y la reflexión. Eran sectores más educados y, por tanto, menos dispuestos a dejarse interpelar por el estricto ethos autoritario que les había permitido a sus padres progresar bajo la tutela de los militares. El descontento juvenil atizado y galvanizado por un movimiento contracultural mundial planteaba nuevos retos, que desde el poder se percibían como amenazas de disolución social.

Con estos antecedentes, se puede entender mejor el objetivo del replanteamiento del lugar de las artes en el aparato oficial. Las nuevas políticas culturales del período de Sánchez Hernández ya no ponían el énfasis en el cultivo y difusión de un canon eurocéntrico de las Bellas Artes, como había sido lo usual entre sus antecesores. Les interesaba más bien interpelar la inquietud rebelde

45 LANZAS, I., Entrevista personal con el autor, 12/4/2013; SiMÁn, J. J., Entrevista personal con el autor, 22/10/2013.

46 Lindo-Fuentes, H. y Ching, E., Modernizing Minds in El Salvador: Education Reform and the Cold War University of New Mexico Press, Albuquerque, 2012.

47 LANZAS, I., Entrevista. 
de los crecientes sectores juveniles a través de las expresiones artísticas novedosas, conectadas con lo popular y lo juvenil. Se abría así una solución para encauzar constructivamente los temidos efectos disolventes de la rebelión contracultural. Estas políticas de inclusión simbólica prometían una renovación carismática del proyecto de modernización autoritaria. Se presentaba así una recomposición del reparto de lo sensible donde lo juvenil ya no se viera como una amenaza sino como la nueva energía renovadora. En este sentido, las nuevas políticas culturales de Béneke eran en realidad una "policía» de la juventud, que buscaban entrar al juego de interpelación diferenciada para fortalecer el orden vigente y conjurar el espectro de una "política» propiamente dicha, es decir como la irrupción de los excluidos, de los «sin parte» ${ }^{48}$.

En el plano artístico, la forma que cobró esta policía juvenil fue la del espectáculo total. Ya había claros antecedentes en la grandilocuencia arquitectónica de la década de 1950, durante el gobierno del coronel Osorio, quien fue el verdadero impulsor de la modernización autoritaria. El estado adquirió un nuevo rostro en un estilo arquitectónico moderno donde se combinaban las últimas técnicas constructivas con las expresiones plásticas más novedosas ${ }^{49}$. Esa capacidad de congregar los distintos lenguajes en producir una obra colectiva era lo que Béneke admiraba del arte dramático japonés y lo que trata de poner en juego en sus experimentos de formación artística.

La venida de los profesores españoles que viajaron luego con Roberto Salomón a Colombia y los apoyos oficiales que recibió el programa de Artes Escénicas en el Bachillerato en Artes, se vieron facilitados por la impresión positiva que ocasionó en las autoridades un singular montaje. El propio Béneke sugirió a los jóvenes coordinadores de los distintos programas del Bachillerato en Artes que era necesario mostrar a las autoridades una muestra vistosa del primer año de trabajo del nuevo equipo del programa. Fue así como el 13 de julio de 1970, se presentó La persecución y asesinato de Jean-Paul Marat interpretado por los internos del asilo de Charenton, bajo la dirección del Marqués de Sade, mejor conocida como el Marat-Sade de Peter Weiss ${ }^{50}$. Participaban allí los directores, los maestros y los estudiantes de los tres departamentos del Bachillerato: Artes Escénicas, Artes Plásticas y Música. El espectáculo contenía acrobacia, decorados vistosos y música con percusión ${ }^{51}$. Era una elección, por lo demás, insólita para ser presentada ante el presidente de la República y sus principales colaboradores. Recordemos que Peter Weiss, propulsor del teatro-documento, era

48 Sobre política y policía, remitir a RANCIÈRE, J., El desacuerdo, política y filosofía, Ediciones Nueva Visión, Buenos Aires, 1996.

49 Gutiérrez Poizat, S., «Premisas para comprender la arquitectura moderna en El Salvador», en: Identidades, revista de ciencias sociales y humanidades, No. 7, julio-diciembre, 2013, pp. 41-57.

50 Velis, C., Las artes escénicas en El Salvador, una historia de amor y heroísmo, Clásicos Roxsil, Santa Tecla (El Salvador), 2002, pp. 83.

51 Salomón, R., Entrevista; Cañénguez, D., Entrevista; Marroquín, S., Entrevista personal con el autor, 13/10/2013; Portillo, P., 8/4/2013; Huezo, R., Entrevista. 
uno de los dramaturgos de izquierda más radicales que se podía señalar en esos años. En la obra, había canciones que se burlaban de los militares, la iglesia y las buenas costumbres burguesas. Los actores que interpretaban a los lunáticos del asilo se desplazaban en el escenario haciendo ademanes provocadores ${ }^{52}$. Parecía la fórmula perfecta para la catástrofe. Y, sin embargo, las autoridades, incluido el presidente, aplaudieron con entusiasmo. La apuesta de Béneke y su equipo había sido un éxito ${ }^{53}$. Era la prueba palpable de que las desbordantes energías juveniles podían ser redirigidas bajo la adecuada guía. Era la "policía» juvenil en marcha. Este era el marco oficial de legitimación del proyecto: el espectáculo total como la archipolítica del estado autoritario renovado, como la sublimación catártica de la rebeldía. Los contenidos revolucionarios del texto de Weiss quedan así eclipsados frente a la inmediatez ética del espectáculo donde se simulaba un cuerpo social renovado que ya no vibraba con ritmos marciales sino con los acordes estridentes y disonantes del rock.

Esta situación paradójica casi hasta el absurdo, corrobora la advertencia de Rancière sobre la indeterminación de los ejercicios disensuales, hasta el más contestario de los lenguajes artísticos puede ser recuperado a favor de la reproducción del orden. Sin embargo, siguiendo su misma idea de la indeterminación de lo estético, no era esta la única lectura posible. Seguramente para los maestros del programa, como Roberto Salomón, esta concesión al poder era parte de un cálculo que, a la larga, permitiría la consolidación de un espacio autónomo y profesional para el teatro. Y asegurarlo, requería algunos sacrificios. Sin embargo, el poder de la maquinaria disensual del nuevo teatro abriría posibilidades imprevistas entre los otros partícipes del experimento: los estudiantes.

Los esfuerzos del poder por convertir los espacios de formación artística en técnicas de una policía juvenil no borraron la memoria de luchas democráticas ni los afectos emancipadores de los becarios, como vimos en la experiencia de formación de Paz y Umaña. Junto a los esfuerzos de sublimar la rebeldía juvenil en una nueva apoteosis del estado moderno, se incuba una práctica teatral de contestación en el seno del aparato oficial. A través de la militancia política, el nuevo teatro se vincula a una serie de prácticas disensuales que se van sumando a subjetivaciones políticas populares. El nuevo teatro se presenta como el escenario de la emergencia de un cuerpo popular que se libera de las cadenas de la dominación. Así se explica la fuerza que anima las intensas búsquedas creativas de esta nueva generación de artistas. Pero esto, a su vez, provoca enfrentamientos cada vez más graves con el aparato represivo del estado autoritario y amargas discusiones facciosas que deterioran las relaciones con los maestros y entre los mismos estudiantes ${ }^{54}$.

52 Portillo, P.. Entrevista.

53 SALOMÓN, R., Entrevista.

54 Rodríguez Díaz, R., Entrevista personal con el autor, 11/1/2013. 
Las ideas del nuevo teatro sobre el colectivo teatral adquieren nuevas significaciones en un contexto histórico como el de El Salvador de mediados de la década de 1970, que se caracteriza por una intensa movilización popular. Este era el entorno en que ocurría el movimiento teatral. Santiago García postulaba que el público destino del Teatro de la Candelaria era «el pueblo obrero organizado ${ }^{55}$. Pero hubo gradualmente que resignarse a un público progresista de clase media mientras las condiciones de lucha de clase no estuvieran dadas $^{56}$. En El Salvador, la intensificación del conflicto social hizo posible que el nuevo movimiento teatral tenga ese público «idóneo» a su disposición.

En este contexto de tensión entre los imperativos políticos y artísticos, el movimiento teatral florece con una intensidad insospechada por sus impulsores $^{57}$. Una gran variedad de grupos teatrales se nutre de los egresados del Bachillerato en Artes. Menciones como ejemplo a Sol del Río 32, Arteria Vital, a Teatro Grupo Experimental (T. G. I.) o al Grupo de Investigación Expresiva Maíz, mejor conocido como Grupo Maíz. Todos ellos son innovadores a nivel de su propuesta estética pero también se acercan a la acción política de las organizaciones de masas, con distinta fortuna. Asumen tareas que van desde las más tradicionales de agitación y propaganda hasta experimentos de teatro foro como los lleva a cabo el Grupo Maíz en las tomas de fábricas ${ }^{58}$.

En la medida en que el prospecto de la guerra se vuelve inminente, se le plantean al movimiento disyuntivas difíciles. El grupo Sol del Río 32 había surgido como una célula del Partido Comunista Salvadoreño que buscaban reclutar adeptos entre los estudiantes del Bachillerato en Artes, sus miembros formaban arte de la Asociación de Estudiantes de Secundaria (AES), que respondía a esa organización política ${ }^{59}$. Pero a medida que se consolidaron como grupo descubrieron que su mejor contribución al proceso era su trabajo artístico. Intentan profesionalizarse y volverse sostenibles con estrategias como la de buscar suscriptores ${ }^{60}$. Consiguen becas para hacer estudios superiores de artes dramáticas en la Unión Soviética. Ya en plena guerra y desde el exilio, optan por desvincularse de su organización que les exigía que regresaran a Centroamérica a apoyar la lucha armada ${ }^{61}$. Grupo Maíz, en cambio, niega desde el principio cualquier posibilidad de pactar con el establecimiento cultural oficial. Se consideran un colectivo de resistencia que hace teatro callejero y se involucra orgánicamente con el movimiento de masas ${ }^{62}$. Algunos de sus

55 GARcía, S., «Un actor de nuevo tipo para un nuevo tipo de teatro» en Teoría y práctica del teatro, Ediciones La Candelaria, Bogotá, 1989, p.5.

56 Aldana, J., o, c, pp. 131-132.

57 Velis, C., o, c, pp. 93-105.

58 PAZ, D., Entrevista.

59 Umaña, Personal Entrevista.

60 Sol del Río 32, «Sistema de socios y amigos» en: El papo, cosa poética, No. 7, 1978, p. 28 .

61 UMAÑA, F., Entrevista.

62 Maíz, Grupo de Investigación Expresiva, «Manifiesto» en: El papo, cosa poética, No. 6, 1977, pp. 30-32. 
miembros pasan a formar parte del Movimiento de Cultura Popular (MCP) y de la naciente estructura de propaganda del Bloque Popular Revolucionario (BPR), frente de masas de las Fuerzas Populares de Revolución (FPL), una de las principales organizaciones guerrilleras de El Salvador. Pero este paso significa en la práctica supeditarse a las órdenes de dirigentes que tienen una visión instrumental de la labor artística. Las opciones del nuevo movimiento teatral parecen reducirse al exilio o la disolución en la organización revolucionaria.

¿Cómo interpretar entonces el sentido histórico de esta experiencia del Nuevo Teatro en El Salvador? ¿Es un producto fugaz de una arrogancia eufórica que, bajo la máscara de la igualdad, esconde fantasías de control autoritario? ¿Es posible discernir formas de praxis artística que subsisten la crítica del espectáculo y el entusiasmo apresurado por descubrir la fórmula mágica por medio de la cual la revolución se hace carne?

Ya en la posguerra, poco después de la firma de los acuerdos de paz de 1992, algunos artistas del antiguo movimiento teatral independiente encontraron un nicho para sobrevivir realizando proyectos para una de las numerosas ONGs que colaboraban en el proceso de pacificación ${ }^{63}$. A unos de ellos, se les ocurrió repetir el experimento del teatro bus, esta vez como una técnica de «desarrollo de la participación ciudadana» e «incentivo de la cultura democrática». El experimento fracasó estrepitosamente. Por más que indujeron a los pasajeros a la discusión, ninguno de ellos se atrevió a intervenir. El entorno social que hacía que los experimentos del nuevo teatro prendieran de inmediato el ánimo popular ya no existía. Años de guerra y de neoliberalismo, habían hecho de las suyas. Ningún pasajero mostró interés en salir de su espacio individual. Si antes había una cierta certeza de la transmisión de significados del autor al público a través de los dispositivos innovadores, era porque la praxis artística estaba inserta en un entorno de intensa subjetivación política popular. En los tiempos consensuales de la transición a la democracia, la participación ciudadana, las ONGs y las nuevas políticas securitarias, la indeterminación estética cobraba nueva contundencia.

Pese a lo anterior, es importante recalcar que las propuestas de Augusto Boal exceden al teatro invisible. Este fue su expresión del período de su carrera cuando estaba en apogeo el entusiasmo de las oleadas emancipadoras que siguieron el triunfo de la Revolución Cubana. Pero su propuesta del teatro del oprimido aspiraba ir más allá del espacio de la representación teatral y de la institución tradicional del teatro, no sólo porque aspiraba abolirlas sino porque reconocía la posibilidad de constituir nuevos espacios de experiencia estética articulados a prácticas de emancipación. En esta nueva praxis dramática, se

63 EspinOza, M., Entrevista personal con el autor, 22/11/2013. 
abría a los sujetos la posibilidad de experimentar las maneras en que la sociedad atraviesa sus cuerpos. En los últimos años de su vida Augusto Boal amplió sus ejercicios teatrales en dinámicas de educación popular y comenzó a hablar de un "teatro legislativo», una versión más atenuada y adaptada a los nuevos tiempos de su "poética del oprimido» ${ }^{64}$. Ello confirma que hay algo del vocabulario teatral con insistencia en la microfísica de los cuerpos en interacción que permite un espacio de reflexión sobre lo social en su célula elemental: un cuerpo semióticamente constituido, al que se le abre la posibilidad de ser reinventado en un nuevo cuerpo emancipado.

Estas formas de experiencia estética fueron posibles en una América Latina, en la cual la modernización no había erradicado del todo la densidad de los espacios de interacción comunitaria. Al presente, esta es una peculiaridad que ya no puede darse por sentada. Es difícil que el teatro, u otra experiencia artística, se vuelva a proponer con el mismo optimismo el parto del nuevo sujeto revolucionario como soñaron estos jóvenes artistas en la década de 1970. Pero lo que vivieron los protagonistas del azaroso movimiento teatral salvadoreño en un período atravesado por paradojas y contradicciones fue una audaz experiencia de libertad que les permitió poner a prueba sus energías para intentar cambiar el pesado mundo que heredaban de un orden social opresivo.

Universidad Centroamericana José Simeón Cañas, El Salvador

RicaRdo RoQue BaLdovinos

[Artículo aprobado para publicación en enero de 2019]

64 BoAL, A., Legislative Theatre, using performance to make politics [1998], trad. Adrian Jackson, Routledge, Londres y Nueva York, 2005. 